R. Hadef, K.P. Geigle, W. Meier and M. Aigner, Soot Characterization with Laser-Induced Incandescence Applied to a Laminar Premixed Ethylene Air Flame, International Journal of Thermal Sciences 49 (2010) 1457-1568.

The original publication is available at www.elsevier.com

http://dx.doi.org/10.1016/j.ijthermalsci.2010.02.014 


\title{
Soot Characterization with Laser-Induced Incandescence Applied to a Laminar Premixed Ethylene
}

\section{Air Flame}

\section{Redjem Hadef ${ }^{1}$, Klaus Peter Geigle ${ }^{2, *}$ Wolfgang Meier $^{2}$ and Manfred Aigner ${ }^{2}$}

${ }^{1}$ Faculté des Sciences et de la Technologie, Université Larbi Ben M’Hidi, Oum El Bouaghi, Algérie

${ }^{2}$ Institute of Combustion Technology, German Aerospace Center (DLR), Pfaffenwaldring 38-40, Stuttgart, Germany

\author{
${ }^{*}$ Corresponding author: KlausPeter.Geigle@dlr.de \\ phone $++49-711-6862-398$, fax $++49-711-6862-578$
}

\begin{abstract}
Laser-induced incandescence (LII) has emerged as a promising non-invasive technique for measuring spatially and temporally resolved soot volume fraction and size. In this investigation we try to assess its performance in more detail by characterizing primary particle sizes using time-resolved LII and soot volume fractions by 2D LII. The experiments were performed at a fixed location in premixed ethylene/air flames burning on a sintered stainless-steel plug (McKenna) burner with varying values of the equivalence ratio for primary particle sizing and on the burner axis for concentration measurements. Maximum soot concentrations follow a power law behavior with equivalence ratio. The primary particle sizes obtained from LII decay curves are in good agreement with the values measured by other techniques and show a clear rise of particle size with equivalence ratio. The data analyzed with the help of a validated LII model will be useful for the further development of soot formation models.
\end{abstract}

Keywords: Premixed flame, Soot, Laser Diagnostics, Heat Transfer 


\section{Nomenclature}

$C_{\text {cal }}$ Calibration constant

$D \quad$ (Primary) particle diameter, $\mathrm{m}$

$D_{m} \quad$ Mean (primary) particle diameter, $\mathrm{m}$

$E_{m} \quad$ Refractive index function

$E_{m}^{*}=0.4$

$F_{0} \quad \mathrm{~J} / \mathrm{m}^{2}$

$q(t)$ Temporal laser intensity profile, $\mathrm{W} \mathrm{m}^{-2}$

$f_{v} \quad$ Soot volume fraction

$h_{\text {cond }}$ Heat transfer coefficient

$h_{i} \quad$ Polynomial coefficient for the temperature dependence of the enthalpy of vaporization of soot

Kn Knudsen number

$M^{0} \quad$ Blackbody spectral radiation, $\mathrm{W} \cdot \mathrm{m}^{-2} \cdot \mathrm{m}^{-1}$

$M_{g} \quad$ Molar mass of gas, $\mathrm{kg} \mathrm{mol}^{-1}$

$M_{v} \quad$ Molar mass of soot vapor, $\mathrm{kg} \mathrm{mol}^{-1}$

$m_{i} \quad$ Polynomial coefficient for the temperature dependence of the molar mass of soot vapor

$m \quad$ Particle mass, kg

$N_{p} \quad$ Number density of the soot particles, $\mathrm{m}^{-3}$

$P \quad$ Pressure, $\mathrm{Pa}$

$p_{i} \quad$ Polynomial coefficient for the temperature dependence of the vapor pressure of soot

$S_{\text {LII }} \quad$ LII signal

$T_{p} \quad$ Particle temperature, $\mathrm{K}$

$T_{g} \quad$ Gas temperature, $\mathrm{K}$ 
$t \quad$ Time, s

$U \quad$ Velocity, $\mathrm{m} / \mathrm{s}$

\section{Greek symbols}

$\alpha_{\mathrm{T}} \quad$ Thermal accommodation coefficient

$\beta \quad$ Mass accommodation coefficient

$\gamma \quad$ Heat capacity ratio $c_{\mathrm{p}} / c_{\mathrm{v}}$

$\Delta H_{\mathrm{v}}$ Enthalpy of vaporization, $\mathrm{J} \mathrm{mol}^{-1}$

$\varepsilon \quad$ Emissivity of soot

$\lambda \quad$ Wavelength, $\mathrm{m}$

$\rho \quad$ Density, $\mathrm{kg} \mathrm{m}^{-3}$

$\sigma_{\mathrm{g}} \quad$ Geometric width of a log-normal distribution

$\phi \quad$ Equivalence ratio

\section{Subscripts}

abs Absorption

c Critical

cond Conduction

det Detection

evap Evaporation

ex Excitation

g Gas

int Internal energy

las Laser 
rad Radiation

$i \quad$ Counter index for sum

v Vapor

\section{Superscripts}

* Average value

\section{List of constants}

$c=299792458 \mathrm{~m} \mathrm{~s}^{-1}$, Speed of light in vacuum

$h=6.62608 \cdot 10^{-34} \mathrm{~J} \mathrm{~s}$, Planck constant

$k_{B}=1.380662 \cdot 10^{-23} \mathrm{~J} \mathrm{~K}^{-1}$, Boltzmann constant

$R=8.314 \mathrm{~J} \mathrm{~K}^{-1} \mathrm{~mol}^{-1}$, Universal gas constant

\section{Introduction}

Soot is formed from combustion processes in locally fuel-rich zones at elevated temperature and consists mainly of carbon, and contains up to $10 \%$ hydrogen on a molar basis, and even more in young soot. Briefly, its evolution proceeds in three chemical and physical steps, as reported by Haynes and Wagner [1], Bockhorn and Schäfer [2]: the formation and growth of large aromatic hydrocarbons and their transition to particles (soot particle inception), the growth of solid particles by addition of components from the gas phase (surface growth), and the coagulation of primary particles to large aggregates (particle agglomeration). The emission of soot from combustors or flames, results from the competition between soot formation and oxidation.

Soot particles smaller than about $300 \mathrm{~nm}$ are known to penetrate deep into the lungs and alveoli and, due to this location and their physico-chemical properties, have a negative impact on health [3]. They are also contributing to adverse changes to the earth's climate through their role in high-altitude cloud formation [4]. As a result of the increased awareness of soot as a pollutant, as well as tighter emission legislation worldwide, the topic of soot formation and oxidation and their interaction with transport processes continues to be the focus of research activities. That spans from extensive fundamental investigations to 
applications of sophisticated optical diagnostics to realistic combustors, both providing support for designing future technical combustion devices. Thus, in order to validate new theories, experimental data describing soot characteristics must be available. As a matter of fact, since most of the relevant information must be obtained by non-invasive, spatially resolved and instantaneous measurements, these needs can be satisfied by using optical techniques.

In many studies absorption/extinction measurements in combination with laser light scattering have been used to provide information on soot characteristics, including soot volume fraction and soot morphology, i.e. primary particle diameter and aggregate size [5-7]. Having the advantage of relatively low cost and ease of application, this combination suffers from various limitations and several disadvantages, such as line-of-sight averaging in extinction measurements (which can be circumvented in certain cases using tomographic inversion techniques [8]) and sensitivity of the detected signal to molecular absorption and fluorescence $[9,10]$.

Over the past 20 years, laser-induced incandescence (LII) has proven in numerous studies to be a useful diagnostic tool for spatially and temporally resolved measurement of soot volume fraction in a wide range of applications, such as laminar and turbulent flames, in-cylinder combustion, and engine exhaust gas characterization. Although instrumentation and interpretation are still under debate as reviewed by Schulz et al. [11] and Michelsen et al. [12], addressing particularly the effects of laser fluence, spectral and temporal gating, optical depth, primary particle size distribution and shape, as well as laser-induced photochemistry [13] and change of particle morphology, LII seems remarkably robust compared to the more conventional techniques for soot characterization including soot volume fraction by gravimetric or light extinction techniques [14], the multi-wavelength emission technique [15], soot morphology (primary particle diameter and aggregate size distribution) determination by laser scattering [16] as well as thermophoretic sampling/transmission electron microscopy particle diagnostic [6,17] or laser-induced fluorescence (LIF) which is based upon measurements of the fluorescence of $\mathrm{C}_{2}$ molecules from vaporized soot $[18,19]$. 
Besides the determination of the soot particle concentration by measuring signal intensity, it is also feasible to infer the mean primary particle size and under certain conditions the primary particle size distribution from the time-resolved LII signals. The first application of LII as a soot particle sizing diagnostic was made by Will et al. [20] followed by Roth and Filippov [21]. In Will's paper, calculations showed that the ratio of the LII signals measured at two different detector gates, the first positioned shortly after the laser pulse and the second delayed by several hundred nanoseconds, can unambiguously be related to the soot primary particle diameter. There are no basic theoretical constraints on the choice of the observation times, however it is suggested to avoid the first vaporization period and to allow a sufficient time span between the measurements for sufficient particle size sensitivity. A good compromise has been found by timing the measurements at $100 \mathrm{~ns}$ and $800 \mathrm{~ns}$ after the excitation laser pulse. The authors demonstrated the method by a two-dimensional measurement of soot particle diameter in a laminar ethylene air diffusion flame and obtained reasonable results. Since this work, rapid progress has been made in recent years to explore various ways to use the time resolved-LII technique as an ultra fine particle sizing tool [22-26]. Assessment of LII as a particle sizing method was done by Vander Wal et al. [22] who compared primary particle sizes evaluated from LII signals with sizes measured using transmission electron microscopy (TEM) and found good agreement at most flame positions. Good agreement between primary particle sizes obtained from LII and from combined scattering/extinction measurements in sooting premixed flames was also obtained by Axelsson et al. [23]. In recent years more experimentalists have applied the TiRe-LII method successfully to soot distributions in diverse combustion systems $[24,25]$ and for the measurement of carbon black properties during the production process, for example Dankers et al. [26].

In the present study, we have characterized the soot formed in laminar premixed ethylene air flames. Soot concentrations were evaluated from measurements of laser-induced incandescence and extinction measurements, and primary soot particle sizes were determined from the temporal profile of the LII signal. Ethylene was selected as the fuel due to its use in many previous studies of soot formation in a 
variety of combustion devices because it is a moderately sooting fuel and can be considered as a surrogate for fuels that contain higher order carbon-carbon bonds. The chosen burner is one of the standard cases agreed upon during the first international LII workshop [11] and the obtained flames fulfill numerical requirements (stable and one-dimensional laminar premixed flame) in order to validate the results of simulations for soot formation models.

\section{Theory}

\subsection{Laser-induced incandescence intensity}

The technique of LII involves heating particles up to typically around $4000 \mathrm{~K}$ with a high-power pulsed laser of several nanoseconds duration followed by cooling down until they reach thermal equilibrium with the combustion environment. The starting point for the mathematical model of the LII phenomena is described by mass and energy balances between a single spherical soot particle of mass $m$ and diameter $D$ heated by an intense laser pulse, and its surrounding at a temperature $T_{g}$ (Fig. 1). Our approach [27] is based mainly on Melton's model [28] in which we have included some substantial modifications as for example temperature dependent thermodynamic parameters for calculating sublimation, conduction, and internal energy storage and wavelength-dependent optical parameters to describe absorption and emission as well as a thermal accommodation coefficient more appropriate for conductive cooling. Thus, the energy equation reads as:

$\rho c \frac{\pi D^{3}}{6} \frac{d T}{d t}=\alpha_{\lambda, l a s} \frac{\pi D^{2}}{4} q(t)+\frac{\Delta H_{v}}{M_{v}} \frac{d m}{d t}-h_{\text {cond }} \pi D^{2}\left(T-T_{g}\right)-\pi D^{2} \int_{0}^{\infty} \varepsilon_{\lambda} M_{\lambda}^{0} d \lambda$

in which the term at the left hand side is the change in the internal energy of the particle. The terms on the right hand side are, in order, the rate of laser energy absorption by the particle, the rate of heat loss by vaporization of the carbon, conduction from the particle to the surrounding gas, and blackbody-like radiation, respectively. Other energy fluxes, for example due to photodesorption, particle annealing and 
soot oxidation as described by Michelsen [29], or thermionic emission of electrons [30] are neglected because these processes are unimportant under the conditions of low to moderately high laser fluences, a regime the present study concerns.

To account for temperature dependence of the particle density and specific heat capacity, we incorporated formulations for these parameters given by Fried and Howard [31] for graphite which are:

$\rho=2303.1-0.073106 T$

$c=\left(R / a_{4}\right)\left\{a_{1}\left(\theta_{1} / T\right)^{2} \frac{\exp \left(\theta_{1} / T\right)}{\left[\exp \left(\theta_{1} / T\right)-1\right]^{2}}+a_{2}\left(\theta_{2} / T\right)^{2} \frac{\exp \left(\theta_{2} / T\right)}{\left[\exp \left(\theta_{2} / T\right)-1\right]^{2}}+a_{3} T\right\}$

where $a_{1}, a_{2}, a_{3}, a_{4}, \theta_{1}$ et $\theta_{2}$ are empirical constants given in Table 1 .

The absorption efficiency of soot is given as:

$\alpha_{\lambda, \text { las }}=\frac{4 \pi D}{\lambda_{\text {las }}} E_{m}$

The value of the absorption function $E_{m}$ depends on the refractive index of soot which presents some uncertainties as it differs significantly between soot from different sources (e.g. different flames) described in literature, especially when different groups, measurement locations, flames and types of diagnostics are compared, see for example overview in [32]. However, in a comprehensive extended study, Krishnan et al. found only weak dependency from fuel and wavelength. Between 400 and $1064 \mathrm{~nm}$, the experimental data of $E_{m}$ by Krishnan et al. [33], taken as representative among values in literature and including values for $\mathrm{C}_{2} \mathrm{H}_{4}$, can be fit to a linear expression as derived in [34]:

$$
E_{m}=0.232+1.2546 \cdot 10^{+5} \lambda
$$

The laser intensity profile $q(t)$ is given by the experimental temporal laser profile $q_{\text {exp }}(t)$ normalized and weighted by the measured laser fluence $F_{0}$, 
$q(t)=F_{0} \frac{q_{\exp }(t)}{\int_{0}^{60 n s} q_{\exp }\left(t^{\prime}\right) d t^{\prime}}$

Sublimation rates are assumed to be kinetically controlled causing a mass loss at the particle surface as:

$\frac{d m}{d t}=\frac{d}{d t}\left(\rho \frac{\pi D^{3}}{6}\right)=-\pi D^{2} \rho_{v} U_{v}$

with the vapor density:

$\rho_{v}=P_{v} \frac{M_{v}}{R T_{v}}$

The velocity of sublimed or vaporized species diffusing away from the particle surface $U_{v}$ is derived from the Maxwell speed distribution defined by the surface temperature and including a vaporization coefficient to account for vaporization kinetics and real gas effects:

$U_{v}=\beta \sqrt{\frac{R T_{v}}{2 \pi M_{v}}}$

The mass accommodation coefficient $\beta$ is assumed to be 0.5 which is comparable to that of $\mathrm{C}$ and $\mathrm{C}_{2}$ measured by Philipps et al. [35]. The final rate equation for the particle diameter becomes:

$$
\frac{d D}{d t}=-2 \beta \frac{P_{v}}{\rho} \sqrt{\frac{M_{v}}{2 \pi R T_{v}}}
$$

An overview of properties of evaporating carbon species in dependence on temperature is given by Leider et al. [36]. The dominant species above $\sim 2000 \mathrm{~K}$ is $\mathrm{C}_{3}$, though all species from $\mathrm{C}_{1}-\mathrm{C}_{7}$ are present in the vapor in different concentrations. In this work, the species $\mathrm{C}_{1}-\mathrm{C}_{7}$ are considered. The vapor pressure, molecular weight of the soot vapor and the enthalpy of vaporization are required as a function of the particle temperature. Smallwood and coworkers [37] derived these expressions from polynomial fits to data from Leider et al. The expressions are:

$$
\Delta H_{v}=\sum_{i=0}^{5} h_{i} T^{i}
$$


$M_{v}=\sum_{i=0}^{5} m_{i} T^{i}$

$P_{v}=\exp \left(\sum_{i=0}^{5} p_{i} T^{i}\right)$

The coefficients for the polynomials 11-13 are listed in table 2 .

It is useful to note that in technical applications the primary particle diameters are typically in the range of 5 to $60 \mathrm{~nm}$. Because the Knudsen number is $>>1$ heat conduction from particles to the surrounding gas occurs within the free-molecular regime. Since our experiments were conducted in flames at atmospheric pressure, the mean free path of gas molecules is much larger than the particle radius, thus the Knudsen number is larger than the value of $5 \sqrt{\gamma \pi / 2}(\approx 7.4)$. In this case, the heat conduction is dominated by molecule-particle collisions and the associated coefficient is described by Filippov and Rosner [38] through the most rigorous expression:

$h_{\text {cond }}=\alpha_{T} \frac{p_{g}}{8} \sqrt{\frac{8 R}{\pi M_{g} T_{g}}}\left(\frac{\gamma^{*}+1}{\gamma^{*}-1}\right)$

where $p_{g}$ and $T_{g}$ are the ambient gas pressure and the gas temperature, respectively, $M_{g}$ the molar mass of the surrounding gas molecules, and $\gamma^{*}$ the average value of the adiabatic constant $\gamma$ of the surrounding gas defined as:

$\frac{1}{\gamma^{*}-1}=\frac{1}{T-T_{g}} \int_{T_{g}}^{T} \frac{d T^{\prime}}{\gamma-1}$

$T^{\prime}$ serves as integration variable for the temperature-dependent parameter $\gamma$, The thermal accommodation coefficient $\alpha_{T}$ is the fraction of heat transferred by a gas molecule that collides with a surface, and depends generally on the nature of gas and particle surface, as well as their temperatures. Before the collision, the colliding gas molecule's temperature equals the bath gas temperature. In the case of complete accommodation, i.e. $\alpha_{T}=1$, the gas molecules leave the particle's surface with the temperature 
of the particle. In the case of zero accommodation, i.e. $\alpha_{T}=0$, the reflected gas molecule is still at the same temperature as before the collision and has effectively not carried away energy from the surface. The value of the accommodation coefficient has a large impact on the heat conduction term and is subject to even greater uncertainly in the literature of LII modeling than $E_{m}$, varying over a wide range from a low value of 0.2 [11] to a high value of 1.0 [39]. An accurate thermal accommodation coefficient for soot/surrounding gas is essential in the determination of the primary particle size and even theoretical modeling has been employed to contribute to better definition of its value [34,40,41]. Hence, it is difficult to choose an agreed value of $\alpha_{T}$ and the most frequently used value 0.3 derived from Hager's measurements [42] made on graphite at temperature of 700-1400 K is employed in this work. By Kirchoff's Law, valid for macroscopic spherical particles, and the extension for arbitrarily sized spherical particles as described in [43], based on the principle of detailed balance, the emission coefficient $\varepsilon_{\lambda}$ is equal to the absorption coefficient. The integral of the last term in Eq. 1 over $\lambda$ based on the $\lambda$-dependence of $E_{m}$ (Eq. 5) can be solved defining an $E_{m}^{*}$, thus yielding:

$$
\pi D^{2} \int_{0}^{\infty} \varepsilon_{\lambda} M_{\lambda}^{0} d \lambda=\pi D^{2} \int_{0}^{\infty} \frac{4 \pi D E_{m}}{\lambda} \frac{2 \pi h c^{2}}{\lambda^{5}\left[\exp \left(h c / \lambda k_{B} T\right)-1\right]} d \lambda=\frac{199(\pi D)^{3}\left(k_{B} T\right)^{5} E_{m}^{*}}{h(h c)^{3}}(16)
$$

while $E_{m}^{*}$ is defined as:

$$
E_{m}^{*}=\frac{\int_{0}^{\infty} E_{m}\left\{\lambda^{6}\left[\exp \left(h c / \lambda k_{B} T\right)-1\right]\right\}^{-1} d \lambda}{\int_{0}^{\infty}\left\{\lambda^{6}\left[\exp \left(h c / \lambda k_{B} T\right)-1\right]\right\}^{-1} d \lambda}
$$

Using a time step of 5 ps, Eqs. 1 and 10 are solved numerically using the fourth-order Runge-Kutta method [44] to derive the particle temperature and size as a function of time during and after the laser pulse. The results of this integration are used to calculate the temporal incandescence radiation collected at a given wavelength $\lambda_{\text {det }}$ (apart from a calibration constant for the optical system) with the help of Planck's radiation function as: 
$S_{L I I}\left(t, \lambda_{\text {det }}\right) \propto \frac{E_{m}}{\lambda_{\text {det }}^{6}}\left[\frac{D^{3}}{\exp \left(h c / \lambda_{\text {det }} k_{B} T\right)-1}-\frac{D_{0}{ }^{3}}{\exp \left(h c / \lambda_{\text {det }} k_{B} T_{g}\right)-1}\right]$

where $D_{0}$ is the initial particle diameter before the onset of evaporation. Note that we have considered the difference between the instantaneous spectral radiation flux and its initial value (without the laser irradiance, last term in Eq. 18) as was done experimentally by adequate background correction.

\subsection{Signal evaluation}

The model shows that particles cool down at different rates due to the different energy loss contributions (relatively high fluence: Fig. 2.a). Thus, the signal emitted during the post-vaporization period, i.e. 30$50 \mathrm{~ns}$, is a function of the size and the temperature of the particle just after the vaporization period, the surrounding gas temperature and the overall cooling rate (Fig. 2.b). Starting from this instant, the particle size can be considered constant. The LII signal after the laser pulse can, in turn be related to the particle size since larger particles cool slower than small ones due to a smaller surface area-to-volume ratio. Therefore, the decay time of the time-resolved signal is dependent on the primary particle size but the exact relation is not that obvious. Primary particle size information can then be obtained from a best-fit comparison of experimental temporal signal decay curves and those calculated.

Particularly in the limit of high laser power and maximum soot particle temperature near its vaporization point, Melton [28] has shown that the intensity of the LII signal $S_{L I I}\left(t, \lambda_{\text {det }}\right)$ for a group of soot particles can be calculated to yield:

$S_{\text {LII }}\left(T_{\max }\right) \propto N_{p} D^{3+0.154 / \lambda_{\text {det }}}$

where $N_{p}$ is the soot particle number density and $\lambda_{\text {det }}$ expressed in microns. For $0.4 \mu \mathrm{m} \leq \lambda_{\text {det }} \leq 0.7 \mu \mathrm{m}$, the LII signal is proportional to the mean soot diameter raised to the power of 3.22 to 3.38 . Thus the laser-induced peak thermal radiation is nearly proportional to the local soot volume fraction, $f_{v}$ :

$f_{v} \cong C_{\text {cal }} S_{\text {LII }}\left(T_{\text {max }}\right)$ 
This theoretical finding is confirmed by various measurements in premixed and diffusion flames [45-48]. The proportionality constant $C_{c a l}$, which is given by the optical system, may be obtained by calibration measurements of flames with a known soot volume fraction or by a single soot concentration value acquired by an independent technique, often based upon extinction measurements $[49,50]$ or gravimetric analysis [51]. A self-calibrating LII procedure has also been described by Snelling et al. [52] where absolute light intensity is measured and no independent calibration is required. Nevertheless, the lightextinction method was used in our approach as it often serves as a reliable calibration tool.

The error in the determined soot volume fraction is the sum of the error in the calibration constant and the error in the LII signal intensity.

$$
\frac{\Delta f_{v}}{f_{v}}=\frac{\Delta C_{c a l}}{C_{c a l}}+\frac{\Delta S_{L I I}}{S_{L I I}}
$$

Sources of uncertainties are discussed in more detail in the next section.

\section{Experiment}

\subsection{Burner}

A water-cooled porous plug burner (McKenna, Holthuis \& Associates) with a fixed total gas flow of 10 SLPM and a maximal uncertainty of the flow controller calibration in the range of $1-2 \%$ was employed to stabilize an atmospheric ethylene/air flame that was radially uniform. Premixed fuel and air was issued from a $60 \mathrm{~mm}$ diameter porous stainless-steel disk surrounded by a $5 \mathrm{~mm}$ wide sintered ring of the same material through which an additional gas flow might shield the flame from horizontal air entrainment. A thick steel plate placed at a height above burner (HAB) of $21 \mathrm{~mm}$ stabilized the flame. The critical equivalence ratio for the visual onset of soot formation is observed at $\phi_{c} \approx 1.8$ which is similar to those values found by D'Alessio et al. [53] and Böhm et al. [54]. This type of flame is easily probed with laser diagnostics. In addition, they offer a direct correlation with kinetic modeling since each 
height correlates to reaction time in the soot formation process. Burner and stabilization geometry have been proposed as a standard test case for the first international workshop on LII [11]. Relative to this definition, the equivalence ratio was extended to the range from $\phi=2.0$ to $\phi=2.5$ for soot concentration measurements and even beyond that for determination of primary particle sizes.

\subsection{Soot concentration measurements by 2 D LII}

The LII signal was excited by a Nd:YAG laser (Spectra Physics GCR 290), with a repetition rate of $10 \mathrm{~Hz}$ and pulse duration of 7-9 ns (FWHM). The $1064 \mathrm{~nm}$ output is preferred because it does not excite undesirable laser-induced fluorescence (LIF) from species such as polycyclic aromatic hydrocarbons associated with soot formation [55]. Our LII experiments for soot concentration mapping were performed in the "plateau region" of LII at a spatially averaged laser fluence of $\sim 0.4 \mathrm{~J} / \mathrm{cm}^{2}$, where the LII signal is approximately independent of the laser fluence as validated by measuring the LII response curve (signal versus laser fluence) and only depends on the soot volume fraction. Too high laser fluences are not recommended [56] because that results in increasingly significant modifications of the soot morphology and surface vaporization, while low laser fluences are not sufficient to heat all particles in the probe volume to a uniform temperature close to soot surface vaporization.

A light sheet is formed with a height of approximately $21 \mathrm{~mm}$ and a waist thickness of about $300 \mu \mathrm{m}$ by a suitable pair of cylindrical negative (focal length $\mathrm{f}=-80 \mathrm{~mm}$ ) and spherical positive $(\mathrm{f}=1000 \mathrm{~mm})$ lenses providing a long focus. For a better definition of the light sheet, a rectangular aperture was employed behind the second lens. The resulting sheet varied by $\pm 15 \%$ vertically while the horizontal profile is assumed to be Gaussian. Laser profile cross section as well as non-negligible sublimation at the employed laser fluence are considered as they contribute to the above mentioned LII response curve and the respective plateau behavior. The induced incandescence emitted perpendicular to the incident sheet was imaged onto an intensified charge coupled device (ICCD, PCO Dicam Pro dual frame) camera. A narrow band interference filter with transmitting wavelength range of 445-470 $\mathrm{nm}$ was placed in front of the 
camera to prevent detection of laser light scattering from soot particles and to reject most background luminosity. An illustration of the experimental layout is shown in Fig. 3.

During the first gate of $40 \mathrm{~ns}$ duration immediately before the laser pulse, the flame luminosity background is detected. The second gate of equal duration starting with the laser pulse is used for detection of the signal. One hundred LII images were acquired for each flame; these were corrected for flame luminosity and for inhomogeneities of the ICCD chip sensitivity.

For quantification of the LII images, a calibration factor is needed relating pixel intensity to soot concentration. In this work and similar to other references mentioned above, laser light extinction was used to calibrate the LII intensities and to obtain absolute values of the local soot volume fraction using the Beer Lambert law:

$\ln \left(I / I_{0}\right)=\frac{6 \pi \quad E_{m}}{\lambda} f_{v} \cdot L$

where $I_{0}$ and $I$ are the intensities of the incident and attenuated light, respectively, $L$ is the optical path length, and $E_{m}$ is used according to Eq. 5.

In this study, the same optical pathway was used by the $532 \mathrm{~nm}$ output of the laser at low power to avoid processes other than extinction in the flame. For monitoring of the incident and transmitted laser intensity portions of the green laser sheet were directed into quartz cells filled with dye solution. The fluorescence was detected in a separate experiment after the LII measurement with the same camera equipped with a filter at $700 \mathrm{~nm}$ to minimize the influence of stray light. In contrast to other published data, where the integral extinction over the whole flame is measured [57], our set-up using the full sheet resolution allows to choose a suitable calibration height after the measurement [58].

Correlating the relative soot volume fractions, i.e. LII intensities, with the average soot volume fraction of the integral extinction provides the following expression for the calibration constant:

$$
C_{c a l}=\frac{\lambda \ln \left(I / I_{0}\right)}{6 \pi E_{m} \int_{0}^{L} S_{L I I}(x) d x}
$$


The error in the calibration constant is mainly attributed to the uncertain value of the refraction index function $E_{m, \lambda}$ which varies in literature and might even vary throughout a sooting flame due to changes in soot size and properties. This and other experimental uncertainties lead to a relative error of the calibration constant for the LII signal of $13 \%$ [59]. The error in proportionality between LII intensity and soot concentration, which is due to the varying particle diameters, is assumed to be $20 \%$ from differences between extinction and LII measurements in laminar premixed flames [48]. The moderate influence of an inhomogeneous laser profile, shot to shot intensity fluctuations or laser absorption is assumed to stay below $5 \%$ for the chosen excitation optics and type of flames.

\subsection{Particle sizing by TiRe LII}

For the determination of the primary particle size, the flame was also excited with a laser wavelength of $1064 \mathrm{~nm}$. To avoid the influence of uncertainties contained in the sublimation sub-model and a change of the initial primary particle size distribution when evaporating, these experiments were carried out with a low laser fluence of $0.12 \mathrm{~J} / \mathrm{cm}^{2}$. Further reduction of fluence lead to a significantly worse signal-to-noise ratio for the equipment employed. A fixed location of $\mathrm{HAB}=12 \mathrm{~mm}$ was chosen for the described variation of equivalence ratio. At this location, Axelsson et al. [23] and Stirn et al. [60] have found no influence of the stabilization plate on the decay curves. The local LII signal decay was recorded perpendicular to the laser sheet with a fast photomultiplier with a horizontal aperture of $0.8 \times 2 \mathrm{~mm}^{2}$, capturing the decay of the signal as the particles cool to ambient temperature. A narrowband filter in the blue $(400 \pm 10 \mathrm{~nm})$ is placed in front of the detector to minimize the interference from scattered light. In order to reduce noise during each experimental run, five hundred LII decay profiles were averaged on a digital oscilloscope with a temporal resolution of $2 \mathrm{~ns}$ and downloaded to a computer. An average signal without laser irradiance was subtracted in order to account for the line-of-sight natural flame luminosity and electronic interferences caused by the laser power supply. Consequently, it is convenient to consider 
the difference $S_{\lambda}$ between the instantaneous spectral radiation flux and its initial value (without the laser irradiance):

$S(t)=S(D, T)-S\left(D_{0}, T_{g}\right)=C \int_{0}^{\infty} \frac{\tau_{\lambda}}{\lambda^{6}}\left[\frac{D^{3}}{\exp \left(h c / \lambda k_{B} T\right)-1}-\frac{D_{0}^{3}}{\exp \left(h c / \lambda k_{B} T_{g}\right)-1}\right] d \lambda$

where $\mathrm{C}$ is a constant parameter and $\tau_{\lambda}$ is the measured spectral transmission function of the optics.

Equation 24 applies to monodisperse primary particle ensembles (uniform size $D_{0}$ ). However, if soot particles in the measurement volume are polydisperse and have a certain size distribution, $P\left(D_{0}\right)$, the measured radiation is the cumulative signal from particles of various sizes present in the measurement volume. Therefore, $P\left(D_{0}\right)$ has a significant impact on the LII signal as the cooling of the laser-heated particles strongly depends on the primary particle size. Thus, the total LII signal $J(t)$ detected at the detector surface is:

$J(t)=N_{p} V_{m} \int_{0}^{\infty} S(t) P(D) d D$

From the kinetics of particle coagulation and from measurements of the primary particle size distribution inside hydrocarbon flames, it is known that frequently the particle size distribution of soot can be approximated by a lognormal distribution with a standard deviation $\ln \sigma$ :

$P(D)=\frac{1}{\sqrt{2 \pi} D \ln \sigma_{g}} \exp \left[-\frac{\left(\ln D-\ln D_{m}\right)^{2}}{2\left(\ln \sigma_{g}\right)^{2}}\right]$

\section{Results}

\subsection{Soot volume fraction measurements}

Figure 4 displays both photos and averaged corrected 2D LII images as a function of the equivalence ratio. The images show that the flames, although not perfectly uniform, are quite homogeneous near the flame axis, where primary particle size measurements were conducted and soot properties are plotted in 
the figures below. More important, we have observed that the flames are highly stable close to the axis and exhibit negligible fluctuations, while those caused by unavoidable left-right flickering are confined to the flame edges. As expected, the incandescence intensity increases with increasing the equivalence ratio, similarly to the visual impression of the flame luminosity.

The corresponding soot volume fraction measured along the burner axis is plotted in Fig. 5. Generally, all profiles exhibit a typical behavior, i.e., onset of soot formation at some distance downstream of the burner, followed by a steady rise due to surface and coalescence growth, and culminating in a plateau region. Here, the particle growth ceases, although the concentration of $\mathrm{C}_{2} \mathrm{H}_{2}$ as a representative growth species was determined to be quite high in the burnt gases of similar flames [61]. This has been attributed to a decrease in soot particle activity [62]. It can be explained by the decreasing concentration of hydrogen atoms, or by the decreasing particle surface caused by coagulation. Decreasing flame temperature due to radiative losses and the cooling influence of the stabilization plate might contribute to this effect [57].

The general shape of the profiles is similar to those of aromatic reaction products, (including benzene, toluene, phenylacetylene, and indene) measured previously by Melton et al. [63] in laminar premixed flames using another fuel: increase up to the peak value, followed by a plateau. However, the levels of several PAH measured in their flame decreased after the peak and then increased again or remained at a lower level. The effect of equivalence ratio on the concentrations of various intermediate chemical species is reported for example in the experimental work $[63,64]$ and summarized by the empirical relationship $X_{i}^{\max }=A_{i} \phi^{n_{i}}$. In this equation, $X_{i}^{\max }$ is the maximum mole fraction of intermediate species $i$ and $A_{i}$ and $n_{i}$ are the corresponding correlation parameters. The sensitivity of species $i$ on equivalence ratio is represented by the parameter $n_{i}$. Similar to the above referenced relationship between molecular flame species concentrations and equivalence ratio we plotted the respective information for soot concentration, assuming that maximal values are almost reached in our highest measurement location. 
The dependence of the maximum soot level on the equivalence ratio is strong (Fig. 6) and rises approximately according to the relation:

$f_{v, \max } \propto\left(\phi-\phi_{c}\right)^{n}$

with $n=2.39$. This dependence is similar to earlier measurements employing different diagnostics to atmospheric laminar premixed $\mathrm{C}_{2} \mathrm{H}_{4}$-air flames investigated by Bönig et al. [65] with $n \sim 2.5$. As recent research [50] provides evidence that extinction measurements at $532 \mathrm{~nm}$ are susceptible to contributions from large PAH, the actual experiments shall be extended to LII calibration in the near infrared in future.

\section{2. $\quad$ Soot primary particle size measurements}

It is well known that the quality of the numerical LII model sensitively influences the mean primary particle size and the primary soot particle size distribution inferred from the experimental time-resolved LII intensities. Therefore, the accuracy of the numerical LII model, in particular the heat conduction submodel, has significant and direct impact on the accuracy of primary particle sizes determined from LII measurements. In spite of advanced developments in the application of LII, significant uncertainty still exists in the numerical modeling of LII intensities during the soot sublimation period, primarily due to the lack of reliable physical parameters required for the incorporation into the respective sub-model such as the vapor pressure and the heat of vaporization under extreme conditions. For this reason, validation of our present model is required and consequently has been conducted with experimental work of known primary particle size [29] where time-resolved LII measurements were performed over a wide range of laser fluences in a coflow $\mathrm{C}_{2} \mathrm{H}_{4}$ diffusion flame at atmospheric pressure. In those experiments, the particles were heated with pulses of $\sim 7 \mathrm{~ns}$ duration $(10 \mathrm{~Hz})$ at $532 \mathrm{~nm}$ provided by an injection-seeded Nd:YAG laser. An aperture was placed in the laser beam and imaged into the flame to provide a homogeneous spatial laser profile, which was characterized using a CCD camera. Since LII is extremely nonlinear with laser fluence up to being independent from it, a homogeneous beam profile is advantageous for interpreting the results. The signal was imaged onto a fast Si photodiode and collected 
over the wavelength range between 570 and $1100 \mathrm{~nm}$. The initial particle diameter $D_{0}$ and the ambient gas temperature $T_{0}$ were assumed to be $35 \mathrm{~nm}$ and $1900 \mathrm{~K}$, respectively, based on previous measurements on the same burner [66].

Figure 7 shows the comparison of our model results for this validation assuming monodisperse primary particles, with the experimental data from Michelsen [29] for several fluences. The model demonstrates qualitatively good agreement with the measurements, rising quickly and decaying slowly at low fluences and rising and decaying faster at high fluences. For fluences below $0.2 \mathrm{~J} / \mathrm{cm}^{2}$ the model yields even good quantitative agreement with the experiments (upper plot, left). Discrepancies between model results and the measurements are most pronounced in the fluence range $0.2-0.4 \mathrm{~J} / \mathrm{cm}^{2}$, shortly after the laser pulse, where rates of evaporative heat loss and mass transfer predominately control the LII behavior. This is due to the insufficiency of sublimation modeling and the neglect of photodesorption and annealing, which are suspect of strongly influencing cooling and mass loss rates [29]. The influence of insufficient sublimation modeling is additionally visible during the first $10 \mathrm{~ns}$ of the process. These difficulties in exactly describing the sublimation at early times of the temporal LII profile are commonly remarked in literature and still an open issue of research. At fluences above $0.7 \mathrm{~J} / \mathrm{cm}^{2}$, dominated by sublimation, our model fails in predicting the LII signal decay. At intermediate fluences $\left(0.4-0.7 \mathrm{~J} / \mathrm{cm}^{2}\right)$ the model description of the LII behavior is acceptable. However, for the fluence range used in our experiments, the agreement is well acceptable.

To determine the mean primary particle size in our experiments in the flat premixed flames, the timeresolved LII signals were evaluated in terms of the mean primary-particle diameter by a profile fitting (from 0 to $1.4 \mu \mathrm{s}$ ) calculated normalized functions to the normalized experimental curves under variation of the mean particle diameter. For a good data fit, the least-squares method was used. As input, the gas temperature $T_{g}$ was assumed to be $1800 \mathrm{~K}$, based on previous measurements in a similar burner [67]. We used a particle size distribution with a geometric standard deviation assumed to be $\sigma_{g}=1.4$, as 
determined by Maricq et al. [68] in this type of flame, being nearly independent of fuel composition. Examples of the measured and best-fit calculated LII signals showing an excellent fit quality are shown in Fig. 8. Although not shown, when choosing a monodisperse distribution the decay behavior is close to mono-exponential and a particle diameter larger by a few nm results. Similarly, variations of $\sigma_{g}$ within a reasonable range result in changing values by some nm for primary particle size. However, we decided to choose the value provided by literature, instead of including $\sigma_{g}$ as a fit parameter.

Fig. 9 plots the variation of primary particle size with equivalence ratio. The soot particle diameter at a fixed location in the flame $(\mathrm{HAB}=12 \mathrm{~mm})$ also increases with increasing equivalence ratio, qualitatively similar to the soot volume fraction, but at significantly smaller slope. These results are in good agreement with the values measured in the same flames by other diagnostics, for example scanning mobility particle sizer, SMPS [60,68], and transmission electron microscopy, TEM [69]. The agreement with other diagnostics shows comparability of the measured parameter, at least for these early stages of soot formation while kinetic soot models capable of specifying particle size can use the provided particle diameters as reference.

\section{Conclusion}

The presented measurements show application of laser-induced incandescence to a set of premixed laminar sooting ethylene/air flames under variation of equivalence ratio. Using the $2 \mathrm{D}$ option with an intensified CCD camera as detector variations of the soot volume fraction distribution with $\phi$ were monitored. Peak soot concentration rises with equivalence ratio relative to the sooting threshold value according to a power law with exponent of 2.39. Future experiments shall employ extinction calibration at $1064 \mathrm{~nm}$ to reduce potential contributions from large PAH.

The presented LII model for analysis of time-resolved LII measurements was validated using experimental LII profiles from literature. Once validated, we used the employed model to deduce mean 
primary particle sizes from a fixed location in the same premixed flames. Synchronously to soot concentrations, the particle size increases from 6 to $19 \mathrm{~nm}$.

Increasing the equivalence ratio correlates with an increase of the concentration of reactive intermediates (for example aromatic species) while at the same time reducing the temperature and therefore favors soot formation [70]. Concerning the soot primary particle size, the obtained results are in good agreement with the values measured by others techniques. The measurements reported in this study can be used to verify detailed chemical kinetic mechanisms describing the formation of soot in combustion.

\section{References}

[1] Haynes B.S., Wagner H.Gg., Soot formation, Prog. Energy Combust. Sci. 7 (1981), 229-273.

[2] Bockhorn H., Schäfer T., Soot Formation in Combustion, H. Bockhorn (Ed.) Springer-Verlag, Heidelberg Germany (1994).

[3] Wilson R, and Spengler J.D., Particles in our air: concentrations and health effects, Harvard University Press, Cambridge, USA (1996).

[4] Jacobson M.Z., Strong radiative heating due to the mixing state of black carbon in atmospheric aerosols, Nature 409 (2001), 695-697.

[5] Santoro R.J., Semerjian H.G.., Dobbins R.A., Soot particle measurements in diffusion flames, Combust. Flame 51 (1983), 203-218.

[6] Dobbins R.A., Megaridis C.M., Morphology of flame-generated soot as determined by thermophoretic sampling, Langmuir 3 (1987), 254-259.

[7] Dobbins R.A., Megaridis C.M., Absorption and scattering of light by polydisperse aggregates, Appl. Opt. 30 (1991), 4747-4754.

[8] Shaddix C.R., Smyth K.C., Laser-induced incandescence measurements of soot production in steady and flickering methane, propane, and ethylene diffusion flames, Combust. Flame 107 (1996), 418-452. 
[9] D’Alessio A., Minutolo P., Gambi G., D’Anna A., Optical characterization of soot, Ber. Bunsenges. Phys. Chem. 97 (1993), 1574-1578.

[10] Lu N., Sorensen C.M., Depolarized light scattering from fractal soot aggregates, Phys. Rev. E 50 (1994), 3109-3115.

[11] Schulz C., Koch B.F., Hofmann M., Michelsen H.A., Will S., Bougie B., Suntz R., Smallwood G., Laser-induced incandescence: recent trends and current questions, Appl. Phys. B 83 (2006), 333354.

[12] Michelsen H.A., Liu F., Kock F., Bladh H., Boiarciuc A., Charwath M., Dreier T., Hadef R., Hofmann M. , Reimann J., Will S., Bengtsson P.-E., Bockhorn H., Foucher F., Geigle K.P., Mounaïm-Rousselle C., Schulz C., Stirn R., Tribalet B., Modeling laser-induced incandescence of soot: a summary and comparison of LII models, Appl. Phys. B. 87 (2007), 712-745.

[13] Goulay F., Schrader P.E., Nemes, L. and Dansson M.A., Photochemical interferences for laserinduced incandescence of flame-generated soot, Proc. Combust. Inst. 32 (2009), pp. 963-970.

[14] Choi M.Y., Mulholland G.W., Hamins A., and Kashiwagi T., Comparisons of the soot volume fraction using gravimetric and light extinction techniques, Combust. Flame 102 (1995), 161-169.

[15] De Iuliis S., Barbini M., Benecchi S., Cignoli F., Zizak G., Determination of the soot volume fraction in an ethylene diffusion flame by multiwavelength analysis of soot radiation, Combust. Flame 115 (1998), 253-261.

[16] Lamprecht A., Eimer W., Kohse-Höinghaus K., Dynamic light scattering in sooting premixed atmospheric-pressure methane-, propane-, ethene-, and propene-oxygen flames, Combust. Flame 118 (1999), 140-150.

[17] Köylü Ü.Ö, McEnally C.S., Rosner D., Pfefferle L.D., Simultaneous measurements of soot volume fraction and particle size/microstructure in flames using a thermophoretic sampling technique, Combust. Flame 110 (1997), 494-507. 
[18] Bengtsson P.E., Aldén M., Soot-visualization strategies using laser techniques: Laser-induced fluorescence in $\mathrm{C}_{2}$ from laser-vaporized soot and laser-induced soot incandescence, Appl. Phys. B 60, (1995), 51-59.

[19] Bengtsson P.E., Simultaneous two-dimensional visualization of soot and $\mathrm{OH}$ in flames using laserinduced fluorescence, Appl. Spectrosc. 50 (1996), 1182-1186.

[20] Will S., Schraml S., Leipertz A., Two-dimensional soot-particle sizing by time-resolved laserinduced incandescence, Opt. Lett. 20 (1995), 2342-2344.

[21] Roth P., Filippov A.V., In situ ultrafine particle sizing by a combination of pulsed laser heatup and particle thermal emission, J. Aerosol Sci. 27(1996), 95-104.

[22] Vander Wal R.L., Ticich T.M., Stephens A.B., Can soot primary particle size be determined using laser-induced incandescence, Combust. Flame 116 (1999), 291-296.

[23] Axelsson B., Collin R., Bengtsson P.-E., Laser-induced incandescence for soot particle size measurements in premixed flat flames, Appl. Opt. 39 (2000), 3683-3690.

[24] Krüger V., Wahl C., Hadef R., Geigle K.P., Stricker W., Aigner M., Comparison of laser-induced incandescence method with scanning mobility particle sizer technique: the influence of probe sampling and laser heating to soot particle size distribution, Meas. Sci. Technol. 16 (2005), $1477-$ 1486.

[25] Kock B.-F., Tribalet B., Schulz C., Roth P., Two-color time resolved LII applied to soot particle sizing in the cylinder of a diesel engine, Combust. Flame 147 (2006), 79-92.

[26] Dankers S., Leipertz A., Will S., Arndt J., Vogel K., Schraml S., and Hemm A., In-situ measurement of primary particle sizes during carbon black production, Chem. Eng. Technol. 26 (2003), 966-969.

[27] Hadef R., Krüger V., Geigle K.P., Tsurikov M.S., Schneider-Kühnle Y., Aigner M., Measurements of soot size and concentration in the laminar premixed flame, Oil \& Gas Science and Technology Rev. IFP 61 (2006), 691-703. 
[28] Melton L.A., Soot diagnostics based on laser heating, Appl. Opt. 23 (1984), 2201-2208.

[29] Michelsen H.A., Understanding and predicting the temporal response of laser-induced incandescence from carbonaceous particles, J. Chem. Phys. 118 (2003), 7012-7045.

[30] McManus K.R., Frank J.H., Allen M.G., Rawlins W.T., Characterization of laser-heated soot particles using optical pyrometry, $36^{\text {th }}$ Aerospace Sciences Meeting \& Exhibit, Reno, USA, 1998, AIAA 98-0159.

[31] Fried L.E., Howard W.M., Explicit Gibbs free energy equation of state applied to the carbon phase diagram, Phys. Rev. B 61 (2000), 8734-8743.

[32] Bouvier Y., Caractérisation de suies et de précurseurs de suies dans des flammes par incandescence induite par laser, $\mathrm{PhD}$ thesis, Université de Lille, 2006.

[33] Krishnan S.S., Lin K.-C., and Faeth G.M., Optical properties in the visible of overfire soot in large buoyant turbulent diffusion flames, J. Heat Transfer 122 (2000), 517-524.

[34] Snelling D.R., Liu F., Smallwood G.J., Gülder Ö. L., Determination of the soot absorption function and thermal accommodation coefficient using low-fluence LII in a laminar coflow ethylene diffusion flame, Combust. Flame 136 (2004), 180-190.

[35] Philipps V., Vietzke E., Flaskamp K., Sticking probabilities of evaporated $C_{1}, C_{2}$ and $C_{3}$ on pyrolytic graphite, Surf. Sci. 178 (1986), 806-812.

[36] Leider H.R., Krikorian O. H., Young D.A., Thermodynamic properties of carbon up to the critical point, Carbon 11 (1973), 555-563.

[37] Smallwood G.J., Snelling D.R., Liu F., Gülder Ö.L., Clouds over soot evaporation: Errors in modelling laser-induced incandescence of soot, J. Heat Transfer 123 (2001), 814-818.

[38] Filippov A.V., Rosner D.E., Energy transfer between an aerosol particle and gas at high temperature ratios in the Knudsen transition regime, Int. J. Heat Mass Tran. 43 (2000), 127-138.

[39] Starke R., Kock B., Roth P., Nano-particle sizing by laser-induced incandescence (LII) in a shock wave reactor, Shock waves 12 (2003), 351-360. 
[40] Daun K.J., Smallwood G.J., Liu F., Molecular dynamics simulations of translational thermal accommodation coefficients for time-resolved LII, Appl. Phys. B 94 (2009), 39-49.

[41] Michelsen H.A., Derivation of a temperature-dependent accommodation coefficient for use in modeling laser-induced incandescence of soot, Appl. Phys. B 94 (2009), 103-117.

[42] Hager J., Glatzer D., Walther H., Kuze H., Fink M., Rotationally excited NO molecules incident on a graphite surface: molecular rotation and translation after scattering, Surf. Sci. 374 (1997), 181190.

[43] Bohren C.F., Huffman, D.R., Absorption and scattering of light by small particles, NewYork, John Wiley \& Sons, Inc. (1983).

[44] Goeken D., Johnson O., Runge-Kutta with higher order derivative approximations, Appl. Numer. Math. 34 (2000), 207-218.

[45] Tait N.P., Greenhalgh D.A., PLIF imaging of fuel fraction in practical devices and LII imaging of soot, Ber. Bunsenges. Phys. Chem. 97 (1993), 1619-1625.

[46] Quay B., Lee T.W., Ni T., Santoro R.J., Spatially resolved measurements of soot volume fraction using laser-induced incandescence, Combust. Flame 97 (1994), 384-392.

[47] Vander Wal R.L., Weiland K.J., Laser-induced incandescence: development and characterization towards a measurement of soot volume fraction, Appl. Phys. B 59 (1994), 445-452.

[48] Appel J., Jungfleisch B., Marquardt M., Suntz R., Bockhorn H., Assessment of soot volume fractions from laser-induced incandescence by comparison with extinction measurements in laminar, premixed, flat flames, Proc. Combust. Inst. 26 (1996), 2387-2395.

[49] Geigle K.P., Schneider-Kühnle Y., Tsurikov M., Hadef R., Lückerath R., Krüger V., Stricker W., Aigner M., Investigation of laminar pressurized flames for soot model validation using SV-CARS and LII, Proc. Combust. Inst. 30 (2005), 1645-1653. 
[50] Zerbs J., Geigle K.P., Lammel O., Hader J., Stirn R., Hadef R., Meier W., The influence of wavelength in extinction measurements and beam steering in laser-induced measurements in sooting flames, Appl. Phys. B 96 (2009), 683-694.

[51] Vander Wal R.L., Zhou Z., Choi M.Y., Laser-induced incandescence calibration via gravimetric sampling, Combust. Flame 105 (1996), 462-470.

[52] Snelling D.R., Smallwood G.J., Gülder Ö.L., Liu F., Bachalo W.D., A calibration-independent technique of measuring soot by laser induced incandescence using absolute light intensity, Appl. Opt. 44 (2005), 6773-6785.

[53] D’Alessio A., D’Anna A., Minutolo P., Sgro L.A., Violi A., On the relevance of surface growth in soot formation in premixed flames, Proc. Combust. Inst. 28 (2000), 2547-2554.

[54] Böhm H., Hesse D., Jander H., Lüers B., Pietscher J., Wagner H.Gg., Weiss M., The influence of pressure and temperature on soot formation in premixed flames, Proc. Combust. Inst. 32 (1988), 403-411.

[55] Santoro, R.J., Shaddix, C.R., Laser-induced incandescence. In Kohse-Höinghaus, K., and Jeffries, J. (Eds.) Applied Combustion Diagnostics, Taylor and Francis, London, 2002.

[56] Vander Wal R.L., Choi M.Y., Pulsed laser heating of soot: morphological changes, Carbon 37 (1999), 231-239.

[57] Axelsson B., Collin R., Bengtsson P.-E., Laser-induced incandescence for soot particle size and volume fraction measurements using on-line extinction calibration, Appl. Phys. B, 72 (2001), 367372.

[58] Tsurikov M.S., Geigle K.P., Krüger V., Schneider-Kühnle Y., Stricker W., Lückerath R., Hadef R., Aigner M., Laser based investigations of soot formation in laminar premixed flames at atmospheric and elevated pressures, Combust. Sci. and Tech. 177 (2005), 1835-1862. 
[59] Geitlinger H., Jungfleisch B., Lehre T., Streibel T., Suntz R., Bockhorn H., Two-dimensional imaging of sizes and number densities of nanoscaled particles, 10th International Symposium on Laser Techniques for Fluid Mechanics , Jul 10-13, 2000, Lisbon, Portugal

[60] Stirn R., Gonzalez Baquet T., Kanjarkar S., Meier W., Geigle K.P., Grotheer H.H., Wahl C., Aigner M., Comparison of particle size measurements with laser-induced incandescence, mass spectroscopy, and scanning mobility particle sizing in a laminar premixed ethylene/air flame, Combust. Sci. and Tech. 181 (2009), 329-349.

[61] Baumgärtner L., Hesse D., Jander H., Wagner H.Gg., Rate of soot growth in atmospheric premixed laminar flames, Proc. Combust. Inst. 20 (1984), 959-967.

[62] Frenklach M., Clary D.W., Gardiner W.C., Stein S.E., Effect of fuel structure on pathways to soot, Proc. Combust. Inst. 21 (1986), 1067-1076.

[63] Melton T.R., Inal F., Senkan S.M., The effects of equivalence ratio on the formation of polycyclic aromatic hydrocarbons and soot in premixed ethane flames, Combust. Flame 121 (2000), 671-678.

[64] Musick M., Van Tiggelen. P.J., Vandooren J., Experimental study of the structure of several fuelrich premixed flames of methane, oxygen, and argon, Combust. Flame 105 (1996), 433-450.

[65] Bönig M., Feldermann C., Jander H., Lüers B., Rudolph G., Wagner H.Gg, Soot formation in premixed $\mathrm{C}_{2} \mathrm{H}_{4}$ flat flames at elevated pressure, Proc. Combust. Inst. 23 (1990), 1581-1587.

[66] R. L. Farrow, private communication.

[67] Stirn R., Geigle K.P, Hadef R., Lammel O., and Meier W., Calibration of 2D LII for Soot Concentration Measurements: Time Resolved Two Color LII in Comparison with Extinction Measurements, $2^{\text {nd }}$ International Discussion Meeting and Workshop 2006: Laser-induced Incandescence, Quantitative interpretation, modelling, application, Bad Herrenalb, Germany

[68] Maricq M.M., Harris S.J., Szente J.J., Soot size distributions in rich premixed ethylene flames, Combust. Flame 132 (2003), 328-342. 
[69] Xu F., Sunderland P.B., Faeth G.M., Soot formation in laminar premixed ethylene/air flames at atmospheric pressure, Combust. Flame 108 (1997), 471-493.

[70] Sunderland P.B., Urban D.L., Stocker D.P., Chao B.H., Axelbaum R.L., Sooting limits of microgravity spherical diffusion flames in oxygen-enriched air and diluted fuel, Combust. Sci. and Tech. 176 (2004), 2143-2164. 
Tables:

\begin{tabular}{|c|c|c|c|c|c|}
\hline$a_{1}$ & $a_{2}$ & $a_{3}$ & $a_{4}$ & $\theta_{1}$ & $\theta_{2}$ \\
\hline 1115 & 1789 & 0.116 & 12.01 & 597 & 1739 \\
\hline
\end{tabular}

Table 1. Parameters for calculating specific heat and heat capacity used in Eq. 3.

\begin{tabular}{|c|c|c|c|}
\hline$i$ & $p_{i}$ & $m_{i}$ & $h_{i}$ \\
\hline 0 & -111.44 & 0.017179 & 205398 \\
1 & 0.090558 & $6.8654 \cdot 10^{-7}$ & 736.6 \\
2 & $-2.7637 \cdot 10^{-5}$ & $2.9962 \cdot 10^{-9}$ & -0.40713 \\
3 & $4.1754 \cdot 10^{-9}$ & $-8.5954 \cdot 10^{-13}$ & $1.1992 \cdot 10^{-4}$ \\
4 & $-2.4875 \cdot 10^{-13}$ & $1.0486 \cdot 10^{-16}$ & $-1.7946 \cdot 10^{-16}$ \\
5 & 0 & 0 & $-1.0717 \cdot 10^{-12}$ \\
\hline
\end{tabular}

Table 2. Coefficients for the polynomial expressions of the vapor pressure, molecular mass of the vapour and enthalpy of vaporization. 
Figure Captions

Figure 1. Energy balance of the LII process.

Fig.2-a. Calculated energy rates $\left(\mathrm{F}_{0}=0.4 \mathrm{~J} / \mathrm{cm}^{2}, \lambda_{\text {las }}=1064 \mathrm{~nm}, \mathrm{~T}_{\mathrm{g}}=1800 \mathrm{~K}, \mathrm{D}_{0}=20 \mathrm{~nm}, \lambda_{\operatorname{det}}=450 \mathrm{~nm}\right)$ showing significant sublimation.

Fig.2-b. Model results for the normalized LII signal from differently sized primary particles $\left(\mathrm{F}_{0}=0.1 \mathrm{~J} / \mathrm{cm}^{2}, \lambda_{\text {las }}=1064 \mathrm{~nm}, \mathrm{~T}_{\mathrm{g}}=1800 \mathrm{~K}, \lambda_{\operatorname{det}}=450 \mathrm{~nm}\right)$.

Figure 3. Experimental set-up of the LII and extinction measurements.

Figure 4. LII images (a) and photographs (b) of the sooting flames.

Figure 5. Soot volume fraction measured along the burner axis.

Figure 6. Final soot volume fraction as a function of equivalence ratio.

Figure 7. Comparison of model results (solid curve) with measured LII temporal profiles [29].

Figure 8. Examples of calculated and measured LII signals.

Figure 9. Soot primary particle size measured by TiRe LII as a function of $\phi$ at $12 \mathrm{~mm}$ HAB in the flame. 


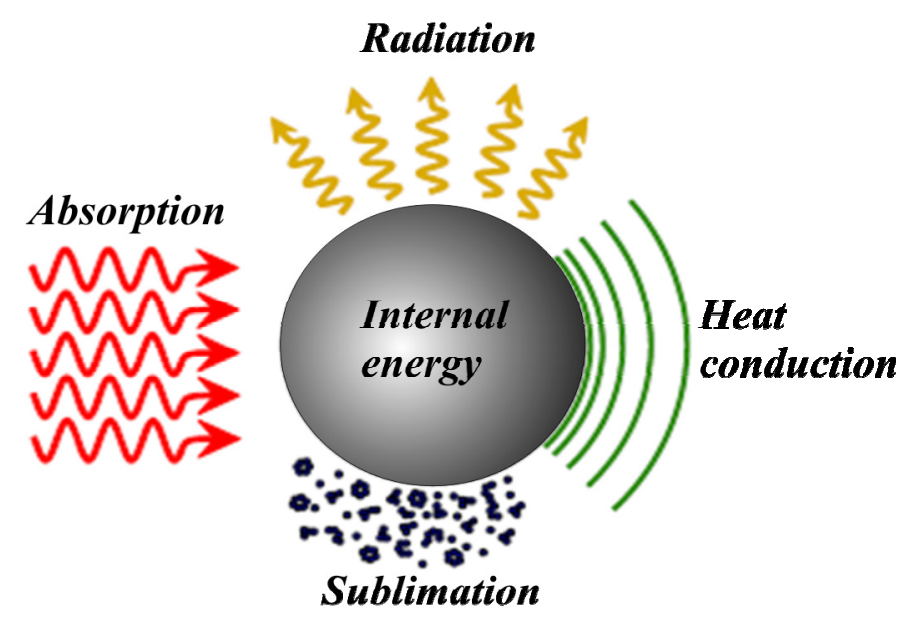

Figure 1. Energy balance of the LII process. 


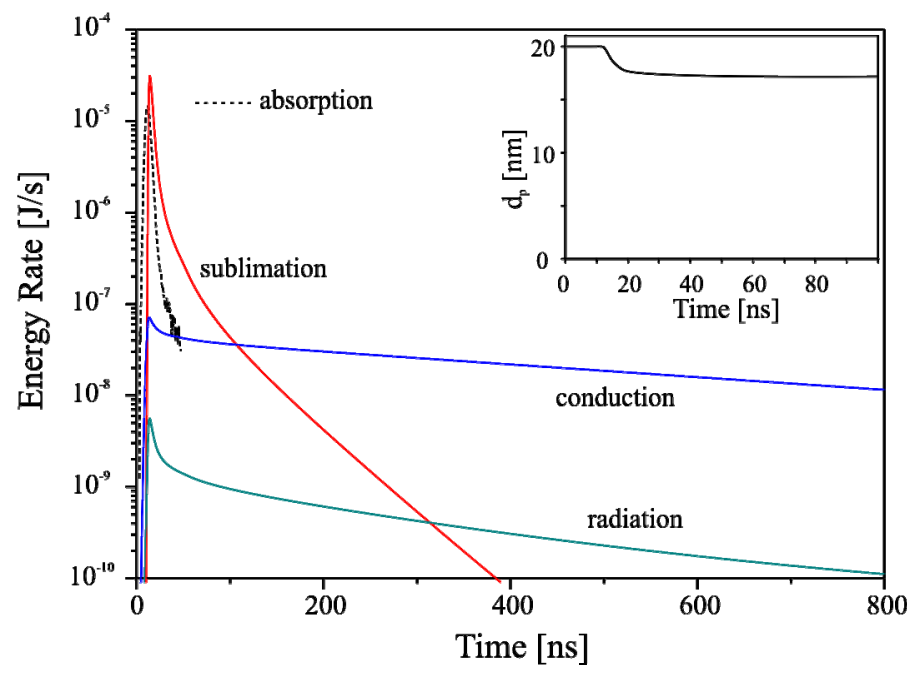

Fig.2-a. Calculated energy rates $\left(\mathrm{F}_{0}=0.4 \mathrm{~J} / \mathrm{cm}^{2}, \lambda_{\text {las }}=1064 \mathrm{~nm}, \mathrm{~T}_{\mathrm{g}}=1800 \mathrm{~K}, \mathrm{D}_{0}=20 \mathrm{~nm}, \lambda_{\operatorname{det}}=450 \mathrm{~nm}\right)$ showing significant sublimation. 


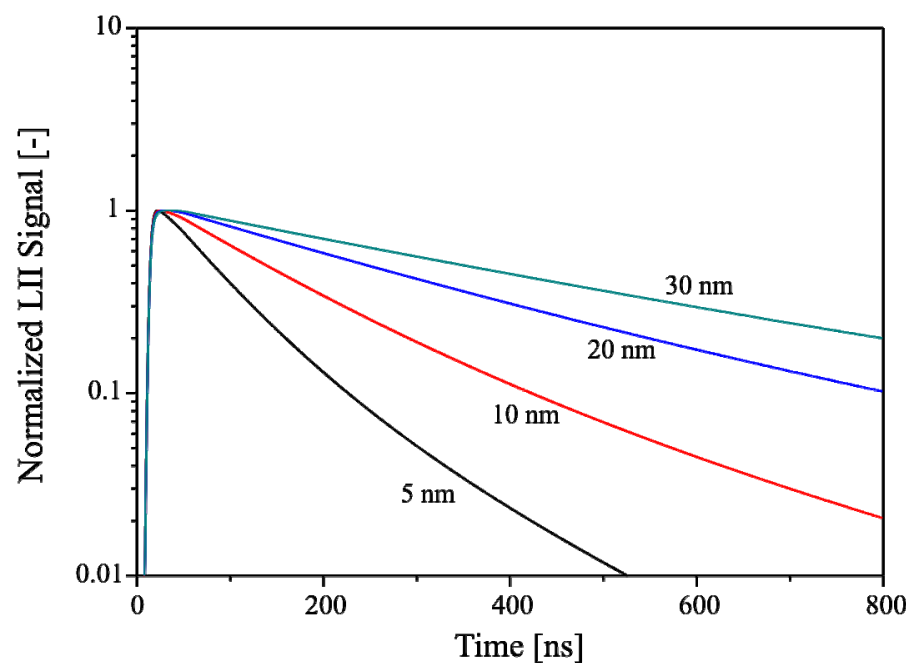

Fig.2-b. Model results for the normalized LII signal from differently sized primary particles $\left(\mathrm{F}_{0}=0.1 \mathrm{~J} / \mathrm{cm}^{2}, \lambda_{\text {las }}=1064 \mathrm{~nm}, \mathrm{~T}_{\mathrm{g}}=1800 \mathrm{~K}, \lambda_{\operatorname{det}}=450 \mathrm{~nm}\right)$. 


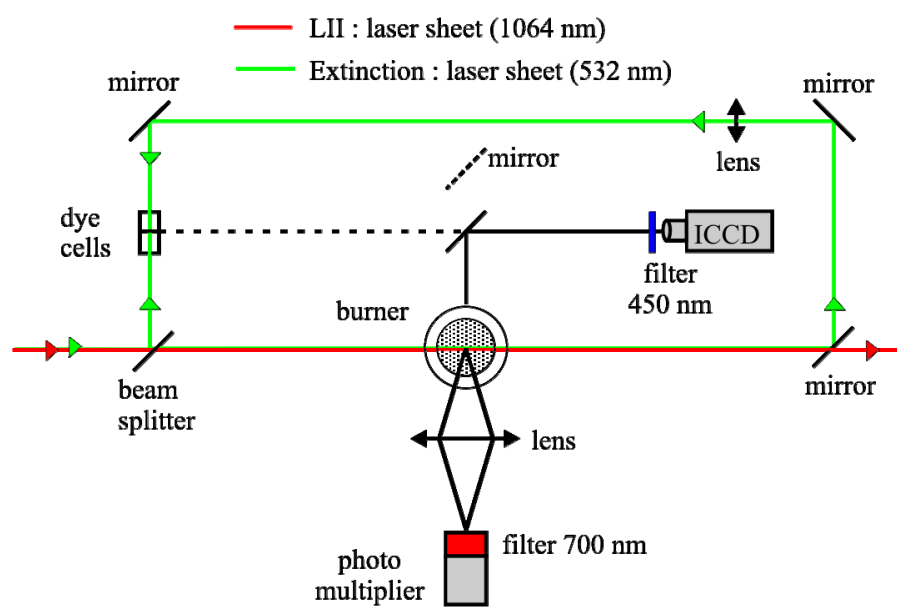

Figure 3. Experimental set-up of the LII and extinction measurements. 
$\max$
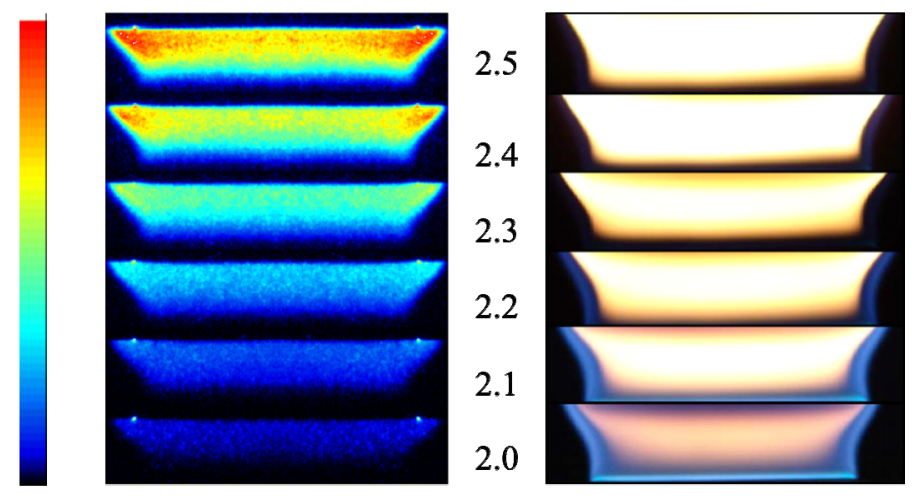

min $\quad$ LII image $\quad \phi \quad$ Photograph

Figure 4. LII images (a) and photographs (b) of the sooting flames. 


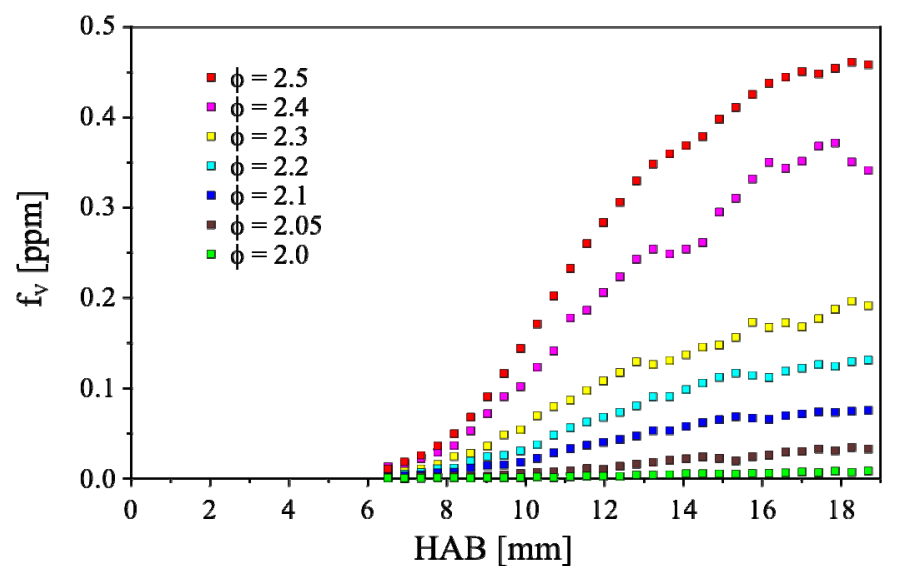

Figure 5. Soot volume fraction measured along the burner axis. 


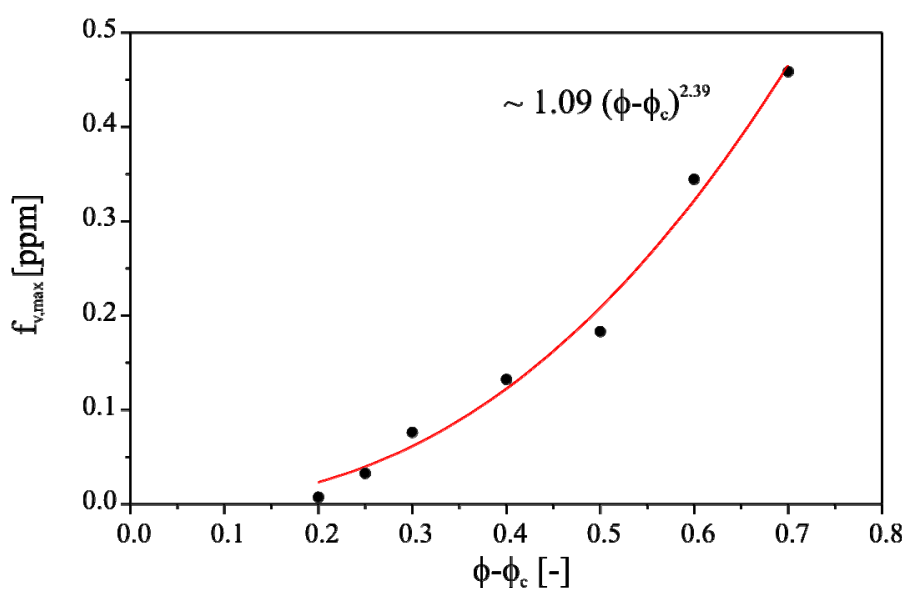

Figure 6. Final soot volume fraction as a function of equivalence ratio. 

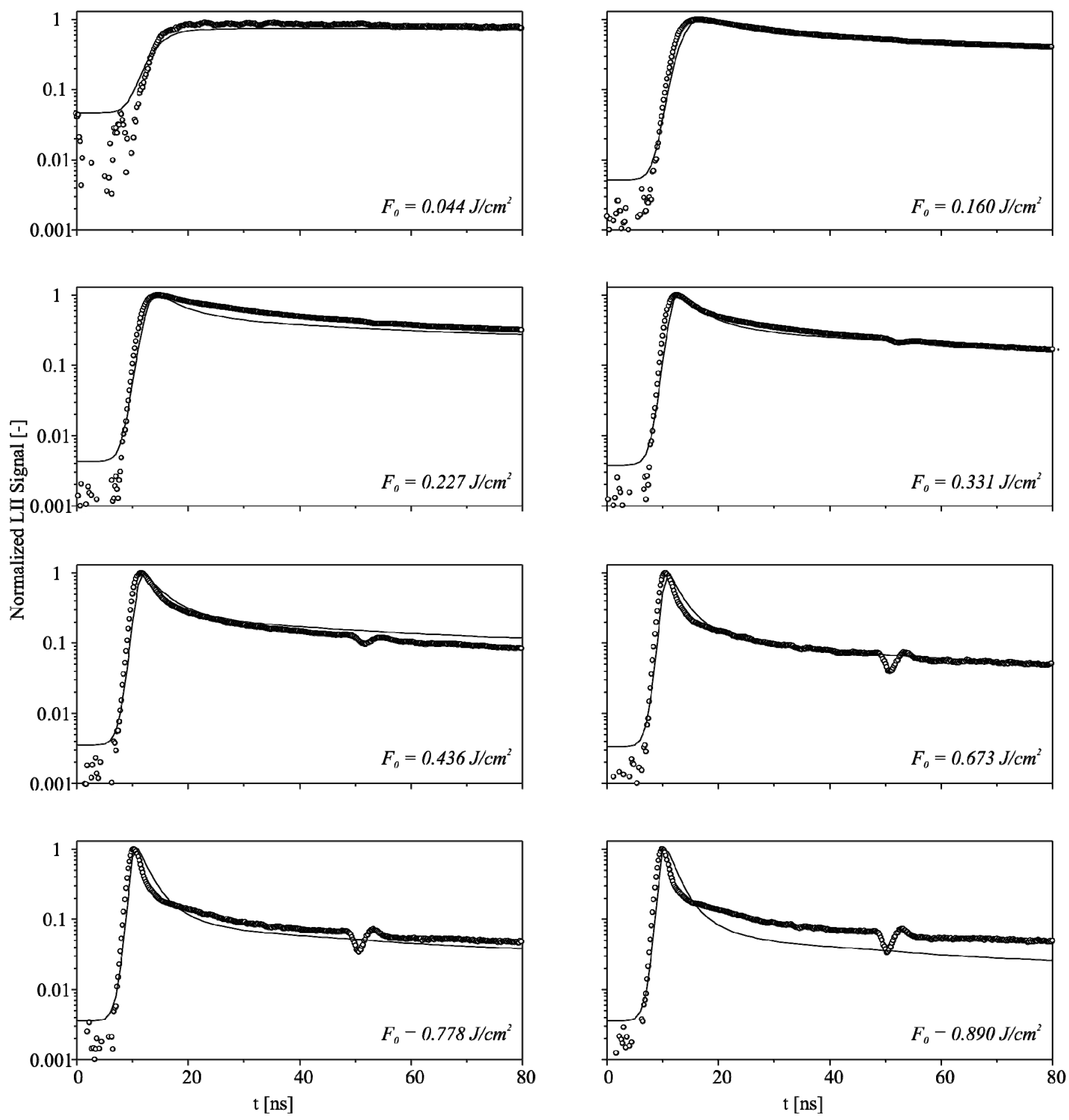

Figure 7. Comparison of model results (solid curve) with measured LII temporal profiles [29]. 

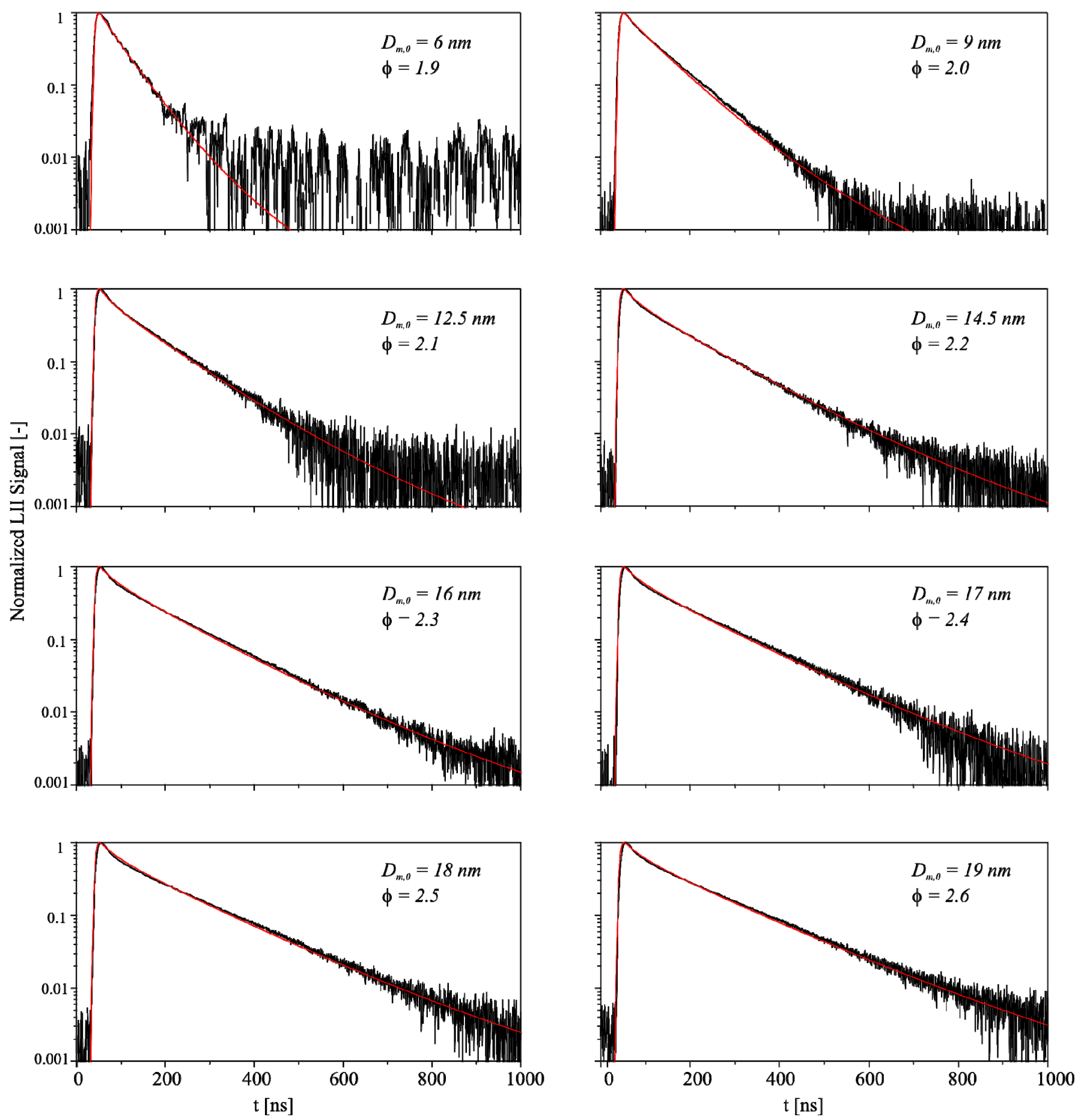

Figure 8. Examples of calculated and measured LII signals. 


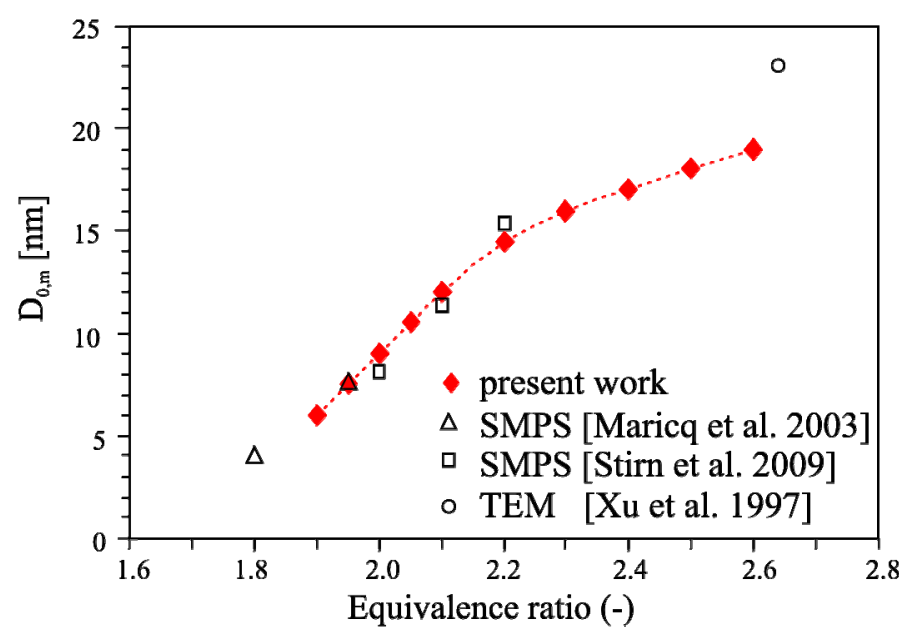

Figure 9. Soot primary particle size measured by TiRe LII as a function of $\phi$ at $12 \mathrm{~mm}$ HAB in the flame. 